\title{
CONCEPÇÕES SOBRE CURRÍCULO DE FORMADORES DE PROFESSORES: O CURSO DE LICENCIATURA EM QUÍMICA DO INSTITUTO DE QUÍMICA DA UNIVERSIDADE FEDERAL DO RIO DE JANEIRO
}

\author{
Elisa Prestes Massena* \\ Departamento de Ciências Exatas e Tecnológicas, Universidade Estadual de Santa Cruz, Campus Prof. Soane Nazaré de Andrade, \\ Rod. Ilhéus-Itabuna, km 16, 45650-000 Ilhéus - BA, Brasil \\ Ana Maria Ferreira da Costa Monteiro \\ Faculdade de Educação, Universidade Federal do Rio de Janeiro, 22290-902 Rio de Janeiro - RJ, Brasil
}

Recebido em 30/11/10; aceito em 22/2/11; publicado na web em 5/5/11

\begin{abstract}
CONCEPTIONS OF CURRICULUM: WHAT TO THINK LECTURERS FROM CHEMISTRY TEACHING COURSE OF THE CHEMISTRY INSTITUTE OF THE UFRJ. In this paper, we discussed the conceptions of curriculum of teachers' trainers from de course of Chemistry from de Chemistry Institute and from the Education School of the Federal University of Rio de Janeiro. We understand that the curriculum results from a social construction, so, we intent to comprehend how happen the constitution of the course's curriculum, based on documents and interviews with the subjects of the research. The study showed that there were competitions for status, resources and territories between the Chemistry Institute and the Education School when the course was created, as well as there were internal competitions in the creation of the disciplines depending on the department of origin of the teachers.
\end{abstract}

Keywords: Chemistry teaching course; lecturers; curriculum history.

\section{INTRODUÇÃO}

A discussão a respeito da formação e das práticas dos formadores de professores vem ganhando espaço nos últimos anos e isto vem acontecendo devido à baixa qualidade da formação dos professores que chegam à Educação Básica. Como os formadores de professores são os principais responsáveis por aquela formação, estes estudos têm se intensificado cada vez mais.

Em sua maioria, os trabalhos que abordam os professores universitários/formadores de professores, quando estes atuam em cursos de licenciatura, têm como problemática principal a ideia de que os sujeitos não tiveram formação voltada para lidar com as questões pedagógicas e, sim, que foram formados apenas para ensinar os conteúdos, de acordo com o antigo modelo de ensino conhecido como " $3+1$ ", onde se cursavam 3 anos de disciplinas específicas e 1 ano de disciplinas pedagógicas. Ademais, os reflexos deste modelo, consequentemente, refletiam-se no curso de formação de professores, tendo o estudante, ao final de seu curso, uma bagagem rica em conteúdos, mas sem compreender como articulá-los às práticas pedagógicas. Nesse modelo, a exemplo da racionalidade técnica, ${ }^{1}$ o professor é concebido como um técnico em que está apto a solucionar problemas mediante a aplicação de teorias e técnicas científicas.

Pretendemos, com esta pesquisa, contribuir para as discussões a respeito das concepções de currículo dos formadores de professores e como estes lidam com tal formação; especificamente, como compreendem essa formação dentro de um Instituto criado, inicialmente, para ser um locus de referência na produção científica em Química no Brasil. Para tal, investigamos a história do currículo do curso de Licenciatura em Química (LIQ), no período noturno, do Instituto de Química (IQ), da Universidade Federal do Rio de Janeiro (UFRJ),

\footnotetext{
*e-mail: elisamassena@yahoo.com.br
}

no período de 1993 a 2005, bem como entrevistamos 7 professores da referida instituição.

De acordo com Goodson, ${ }^{2-8}$ o currículo é construído socialmente pelos sujeitos e essa atuação implica no debate curricular que envolve certo conflito por status, recursos e território. Assim, compreender a história do currículo de um curso passa, também, por entender o envolvimento desses sujeitos na construção desse currículo, o que, por outro lado, contribui para a compreensão das práticas de formação desses formadores de professores. Segundo aquele autor, quando se considera as disciplinas escolares, há três hipóteses, passíveis de verificação: que as disciplinas escolares não são monolíticas, isto é, são amálgamas mutáveis, resultantes de apropriações de subgrupos e tradições; na consolidação da disciplina escolar, há um distanciamento das tradições utilitárias e pedagógicas que foi quem as originou em direção às tradições acadêmicas garantidoras de sua consolidação e, que o debate curricular envolve conflito por status, recursos e território. Assim, intencionamos compreender se essas hipóteses se apresentam para as disciplinas acadêmicas do curso investigado.

As discussões sobre a possibilidade de criação do curso foram iniciadas ainda em 1992 e o corpo de professores presentes à reunião de Congregação, ${ }^{9}$ realizada em 14/7/92, manifestou-se preocupado quanto à precariedade do sistema de segurança, transporte e sobre a falta de recursos financeiros para atender à compra de reagentes e equipamentos para os laboratórios que atenderiam ao novo curso de graduação. No entanto, os esclarecimentos da direção do Instituto de que a criação dos cursos noturnos na UFRJ, de forma geral, teria o apoio do Programa MEC-BID permitiram que a implantação e implementação deste curso no IQ fosse aprovada por unanimidade. ${ }^{10}$ Essas discussões tiveram relação com a aprovação da Lei ${ }^{\circ}$ 8.539, de 22/12/92, que autorizava o Poder Executivo a criar os cursos noturnos de licenciatura em instituições de ensino superior (IES) vinculadas à União. Na década de 1990, foram criados alguns cursos noturnos pelo Brasil, e exemplo disso são as experiências 
relatadas por Santos et al. ${ }^{11}$ sobre o curso de Licenciatura em Química noturno da UnB, criado em 1992, tendo como justificativa a deficiência de professores da área e a ocupação de espaços ociosos da universidade pública, assim como defendem Mazzetto et al., ${ }^{12}$ quando falam sobre o curso de Licenciatura em Química da UFC, criado em 1995, que apresentava três problemas básicos: estrutura curricular, desarticulação entre as disciplinas específicas e pedagógicas e infraestrutura precária.

\section{A PROBLEMÁTICA}

A formação de formadores vem sendo discutida nos últimos anos e isso pode ser observado em alguns trabalhos que surgiram, tratando, de alguma forma, essa temática. ${ }^{13-16} \mathrm{Em}$ sua maioria, esses trabalhos apontam que o professor universitário não é preparado em sua formação para ser um futuro formador de professores, uma vez que os cursos privilegiam a preparação para a pesquisa em detrimento da docência. Neste sentido, existiriam lacunas de cunho pedagógico em sua formação e os professores teriam que suprir as carências de sua formação atuando na prática e assumindo, por sua conta, uma atitude reflexiva em sua prática docente. No entanto, esta questão é delicada de ser modificada na prática, pois, de acordo com Maldaner (p. 289), ${ }^{17}$ "a formação do professor não é vista como uma preparação específica para a produção da própria atividade profissional. Cada qual acha que pode ser professor sabendo, apenas, a matéria que vai lecionar". A ideia que vem à tona é de como se o conhecimento específico fosse condição suficiente para ser um bom professor. Pergunta-se, então: e o que é o bom professor? Segundo Cunha, ${ }^{18}$ o bom professor agrega uma série de aspectos que abarca a influência da família com relação a valores, a sua história enquanto aluno, sua relação com ex-professores, o saber que constrói da própria experiência enquanto docente, a formação pedagógica e a influência de práticas de pessoas que admira. Outro aspecto a ser considerado, e que também é citado por Esteves, ${ }^{19} \mathrm{faz}$ referência ao ensino superior tradicional, uma vez que, segundo essa autora, o mesmo sempre foi centrado no professor e em sua ação. No entanto, ultimamente, essa forma de ensino vem sendo criticada e os processos formativos foram propostos a serem centrados nos estudantes e na aprendizagem. No entanto, a referida autora chama a atenção para a necessidade de uma mudança em relação ao enfoque predominante, aquele do ensino como transmissão (centrado no professor) para o ensino enquanto incitação (proporcionado pelo professor). Com isso, é preciso considerar quais são os objetivos/ fins a alcançar no terreno da formação pelos docentes de determinada instituição. Em outros termos, é preciso pensar sobre como compreender o currículo da formação de professores.

\section{O CAMINHO METODOLÓGICO E OS SUJEITOS DA INVESTIGAÇÃO}

Pretendemos investigar as concepções de currículo de professores formadores do curso de Licenciatura em Química da UFRJ e que atuam tanto no IQ quanto na FE, formando futuros professores que irão atuar na Educação Básica.

Este estudo é de natureza qualitativa e que, de acordo com Bogdan e Biklen ${ }^{20}$ (p. 16), "privilegia, essencialmente, a compreensão dos comportamentos a partir da perspectiva dos sujeitos da investigação". Procura-se dar voz a quem "fala", quem é entrevistado na pesquisa, sujeitos das ações e iniciativas em análise. Mas a "fala" é uma versão dos fatos.

Assim, nesta investigação, optamos por realizar uma pesquisa documental e utilizar entrevistas, visto que, de acordo com Macedo, ${ }^{21}$ os documentos nos permitiriam
[...] acessar os contextos macro sociais e culturais, outros que nos aproximam da instituição estudada e outros ainda mais especificamente relacionados ao currículo ou aos atores curriculares ( $p$. 144).

enquanto que as entrevistas nos auxiliariam a entender a participação e as concepções dos sujeitos investigados sobre o currículo estudado e suas práticas de formação.

Com isso, a intenção foi a de que o material obtido com as entrevistas fosse contrastado e complementado com outras informações, obtidas a partir dos documentos que compõem o processo de criação do curso de Licenciatura em Química, dentre os quais as atas de Congregação do IQ, memorandos, correspondências entre órgãos internos e externos à universidade, bem como documentos disponibilizados pela Faculdade de Educação (FE), tais como relatórios e uma proposta de reorganização curricular. ${ }^{22}$

$\mathrm{Na}$ pesquisa foram entrevistados 7 sujeitos, sendo a entrevista composta de seis questões estruturadas (Quadro 1). ${ }^{23}$

Quadro 1. Roteiro com questões estruturadas para a entrevista

\section{Questão}

1. O que você sabe sobre a constituição do currículo da Licenciatura em Química na UFRJ?

2. Como foram escolhidas as disciplinas?

3. Houve interesse dos departamentos em participar do curso? E da FE?

4. Todos os departamentos deste Instituto/Faculdade ofereceram disciplinas nesse curso?

5. Você acompanhou as reformas curriculares realizadas $(1997,2003$, 2005)?

6. Qual a avaliação que você faz ao currículo do curso considerando essas reformas?

Além de explicar os motivos da pesquisa, tivemos como objetivo compreender a participação dos sujeitos no curso de LIQ e como esses atores se viam enquanto formadores de professores. Tentamos compreender também as disputas internas na construção social do currículo, bem como a luta de forças dentro do campo da universidade em que os Institutos (de Química, Física e Matemática) se agruparam para formar um grupo coeso e discutir questões relativas à criação dos cursos noturnos com a Faculdade de Educação.

Os sete sujeitos entrevistados apresentavam várias origens, quais sejam: um de cada departamento do IQ (DQA, DBQ, DFQ, DQI, DQO); um do departamento de Didática (FE) e um do departamento de Fundamentos da Educação (FE). Como estávamos interessados em questões desde a época da criação do curso, buscamos por ex-coordenadores, ex-diretores do IQ, ex-diretores de Graduação, pessoas que eram mencionadas nos documentos e que, de alguma forma, haviam participado de discussões importantes à época. Ao mesmo tempo, nos interessava ouvir professores formadores que haviam lecionado desde a criação do curso e que possuíam uma relação mais intensa com esse projeto de curso. Consideramos na escolha dos professores a serem entrevistados a atuação no curso de LIQ que abrangeu um período de 2 a 20 anos.

É importante ressaltar que, no estudo em questão, optamos também pelo trabalho com a história oral, uma vez que ela, de acordo com Alberti ${ }^{24}$ (p. 18), é um método de pesquisa “que privilegia a realização de entrevistas com pessoas que participaram de, ou testemunharam, acontecimentos" que se pretende investigar em um período histórico previamente definido; neste caso, de 1993 a 2005.

Outro aspecto importante ressaltado pela mesma autora é que as entrevistas passam a ter estatuto de documento e, como têm seu 
registro gravado e transcrito, documentam uma versão do passado. Nesse sentido, a história oral foi utilizada como metodologia de pesquisa e contribuiu para a construção da nossa versão sobre o período investigado, permitindo que se pudessem identificar interesses e ideologias presentes para a compreensão das formas de atuação, interesses, disputas e conciliações dos atores envolvidos, neste caso, os professores formadores tanto do IQ, quanto da FE.

Outro ponto a se considerar é que os sujeitos investigados representavam gerações distintas e que, por isso mesmo, apresentaram linguagem, cultura e saberes distintos do entrevistador, mesmo quando interagiam e dialogavam sobre o mesmo assunto.

As entrevistas foram realizadas nos próprios locais de trabalho, sendo importante ressaltar também que todas/os entrevistados autorizaram a gravação em áudio, o que facilitou o trabalho posterior de transcrição. Além disso, durante o período da entrevista foram realizadas anotações em caderno de campo. Uma vez feita a transcrição, constatamos que as entrevistas duraram em média $50 \mathrm{~min}$, mantendo-se os sujeitos da pesquisa no anonimato.

\section{A CONSTRUÇÃO E ANÁLISE DOS DADOS}

Para proceder à análise dos "dados", entendendo que nada é realmente "dado" e tudo é de fato construído pelo olhar e trabalho do pesquisador, nos apoiamos em Moraes e Galiazzi (p. 7), ${ }^{25}$ entendendo que estes autores nos auxiliaram com a análise das entrevistas transcritas e dos documentos, em que estes foram submetidos à análise textual discursiva (ATD), "uma metodologia de análise de dados e informações de natureza qualitativa com a finalidade de produzir novas compreensões sobre os fenômenos e discurso".

De acordo com os autores supracitados, essa metodologia situa-se entre a análise de conteúdo e a análise do discurso. Esta metodologia vem sendo ultimamente bastante utilizada em pesquisas no ensino de Ciências para a interpretação e sistematização dos resultados. ${ }^{26-28}$

As entrevistas, em média com 50 min de duração, foram transcritas e cada indivíduo recebeu um codinome. Os dados gerados foram tratados segundo análise textual discursiva (ATD) que, segundo Moraes e Galiazzi, em uma primeira leitura, permite que se faça a fragmentação dos textos, do corpus da análise que, neste trabalho, é considerado como sendo o conjunto das 7 entrevistas transcritas, onde ocorre mesmo o processo de unitarização. Tais autores compartilham do entendimento de que toda leitura já tem em si implícita uma interpretação. Nesta etapa da unitarização, há a desmontagem dos textos, onde é importante focalizar novos detalhes e componentes que fornecem um novo sentido ao texto sem se perder de vista os objetivos da pesquisa.

Nesse sentido, na pesquisa em questão, procuramos compreender não somente o óbvio explicitado pelos sujeitos entrevistados, mas também as subjetividades e questões presentes na medida em que se transcorria o desenvolvimento da pesquisa de campo e que, ao mesmo tempo, iam sendo desvendadas, juntamente com o levantamento histórico documental, as disputas de poder, os grupos hegemônicos e as relações de forças entre as instituições envolvidas na criação do curso de formação de professores de Química. ${ }^{29} \mathrm{Com}$ isso, não pretendemos aqui "aplicar" uma metodologia para a análise das transcrições simplesmente, mas sim compreender o que havia por trás dos depoimentos gerados pelos entrevistados. Segundo Moraes (p. 192), ${ }^{30}$ "os materiais textuais constituem significantes a que o analista precisa atribuir sentidos e significados".

Com a desconstrução dos textos, a unitarização fez com que fossem destacados novos elementos e surgissem, segundo Moraes (p. 192), as unidades de análise ou unidades de significado ou unidades de sentido. Sendo assim, optamos por denominar de unidades de sentido os elementos constituintes da desconstrução dos textos.
A etapa posterior foi aquela denominada por Moraes e Galiazzi ( $p$. 12) como sendo o "estabelecimento de relações" entre as unidades de sentido similares, formando assim "conjuntos que congregavam elementos próximos, resultando daí sistemas de categorias." Com isso, as unidades de sentido foram submetidas a um processo de categorização que considerou aspectos relevantes presentes no roteiro da entrevista estruturada, mas que não considerou categorias pré-estabelecidas para o corpus analisado. A categorização foi feita, então, considerando o referencial teórico da pesquisa e o que se pretendia alcançar com as questões da entrevista, o que possibilitou, em uma próxima etapa, a construção do metatexto: o texto construído resultado das análises das categorias elaboradas.

Assim, as unidades de sentido foram congregadas em categorias, sobre as quais discutiremos: Disciplinas, Currículo, Reformas curriculares, Concepção de formação de professores do curso.

\section{RESULTADOS E DISCUSSÃO}

\section{Um breve histórico do curso de Licenciatura em Química da UFRJ}

Com a análise documental, observamos que a matriz curricular do curso se apresenta no modelo da racionalidade técnica, apresentando as disciplinas específicas de um lado e as pedagógicas de outro. Algumas disciplinas específicas foram 'aproveitadas' do curso de Química com atribuição tecnológica, como podemos observar na fala de Cristina, uma ex-coordenadora do curso que relata que

“[... ] nas reuniões de centro, estava se discutindo fazer uma Licenciatura noturna. Começou a discussão e dentro do Instituto de Química, os departamentos começaram a propor as disciplinas; algumas disciplinas eram as que já estavam no currículo novo do curso de Química que tinha iniciado a implantação em (19)90. Quando eu cheguei, em (19)91, tinha um ano só de implantado. Eu fiz o resto da implantação desse currículo, e, depois algumas daquelas disciplinas foram aproveitadas para Licenciatura e outras foram criadas especificamente para Licenciatura."

As disciplinas pedagógicas apesar de iniciarem no $3^{\circ}$ período não dialogam com as específicas, sendo tal ideia mantida até o final do curso. Outra característica importante é quanto ao posicionamento do estágio supervisionado que é realizado no último ano do curso, isto é, a presença de uma ideia na qual a teoria deve acontecer em um primeiro momento e, posteriormente, ser realizada a prática com a aplicação da técnica. Isto, de acordo com Gómez (p. 96), acontece na racionalidade técnica e prevê a formação de um profissional técnico dotado de todo ferramental técnico-científico "que aplica com rigor as regras que derivam do conhecimento científico". Outro aspecto importante a ser citado é o não entendimento entre químicos e pedagogos na então elaboração daquilo que seria o primeiro currículo do curso de LIQ. Isso pode ser observado em outra fala de Cristina, quando cita a mesma época em que participava de algumas reuniões na Faculdade de Educação. A respeito dessas reuniões, faz o seguinte relato:

“nessa época, a gente participava de algumas reuniões lá na Faculdade de Educação, onde sentavam lá na mesa de reuniões todos os pedagogos e o pessoal do CCMN: Física, Matemática, Química. E a gente não se entendia, eles não entendiam o que a gente falava, nem a gente entendia o que eles falavam. Era um horror. Foram várias reuniões, varava a tarde, assim, pela noite e a gente não chegava, nunca chegamos, a um denominador comum." 
A primeira matriz curricular do curso investigado data de 1993, e o curso de LIQ, durante o período investigado, passou por três modificações curriculares, nos anos de 1997, 2003 e 2005. Essas modificações significaram exclusões/inclusões de disciplinas do Instituto de Química, Instituto de Física, Departamento de Letras Vernáculas, a Faculdade de Educação e o Instituto de Filosofia e Ciências Sociais; no entanto, em média, o currículo manteve durante esses anos 44 disciplinas a serem cursadas.

\section{Concepções de formadores sobre o currículo da Licenciatura em Química}

Nesta etapa da pesquisa foram analisadas as categorias Disciplinas, Currículo, Reformas curriculares e Concepção de formação de professores do curso e buscou-se compreender, por meio dessa análise, os entendimentos da concepção de currículo que os formadores de professores possuíam a respeito do curso em questão. Outro desdobramento foi compreender a importância do curso de Química com atribuição tecnológica, oferecido no período diurno e com o qual grande parte do corpo docente estava envolvida.

$\mathrm{Na}$ categoria Disciplinas foram analisadas as respostas dos professores referentes às discussões realizadas nos departamentos anteriormente à criação do curso investigado, às exclusões e inclusões de disciplinas na matriz curricular, como as disciplinas eram compreendidas e como ocorriam as relações de poder no interior da instituição analisada. Isto pode ser observado na fala a seguir.

“[...] nas reuniões de Centro, estava se discutindo fazer uma Licenciatura noturna. Aí, começou a discussão, e dentro do Instituto de Química, os departamentos começaram a propor as disciplinas, algumas disciplinas eram as que já estavam no currículo novo, do curso de Química, que tinha iniciado a implantação em 1990. Quando eu cheguei, em 1991, tinha um ano só de implantado. Eu fiz o resto da implantação desse currículo, e, depois, algumas daquelas disciplinas foram aproveitadas para Licenciatura e outras foram criadas especificamente para Licenciatura. [...]"(Cristina)

Assim, a matriz curricular inicial foi construída e, posteriormente, temos o depoimento do professor do Departamento de Inorgânica (DQI) a respeito dessa construção:

\section{"[...] nosso departamento participou bastante, inclusive foi o único departamento que sonhava em ter um curso idêntico ao curso diurno, tanto é que nós mantivemos todas as nossas disciplinas. Nós não queríamos fazer um curso mais fraco, diferente, com outra abordagem à noite. E mantivemos até hoje... o departamento mantém as disciplinas no mesmo formato que para o curso com atribuição tecnológica diurno e o curso noturno de Licenciatura."(Danilo)}

No entanto, a formação de professores continuava sendo baseada no modelo conteudista, como pode ser observado ainda em um fragmento do discurso de Danilo, do DQI:

“[...] o nosso departamento não tem nenhum especialista de ensino de Química, acho que nenhum professor é licenciado. Então o que a gente discutia realmente era que esses futuros professores tivessem um embasamento de conteúdos forte. Então a nossa discussão era em cima disso.” (Danilo)

No entanto, apesar de ter este pensamento, compreendia que era preciso ter outra abordagem para o curso de formação de professores, como está explicitado abaixo:

“[...] essa abordagem que o professor dá, claro às vezes o mesmo programa, mas a abordagem, o tratamento tem que ser diferenciado porque o profissional vai ter o perfil totalmente diferente do Engenheiro, do Químico com atribuição tecnológica. [...]" (Danilo)

Por outro lado, Reinaldo, professor do DQA, possuía como justificativa para a modificação dos conteúdos do curso de LIQ a ideia de que este não deveria servir de 'trampolim' para o curso diurno. Tal argumento pode ser observado em sua fala a seguir:

"Na época, tinha-se uma grande preocupação, com as pessoas usarem esse curso como trampolim para passar para o curso diurno. Eu vou fazer um vestibular para Licenciatura que é mais fácil, eu entro e depois eu peço transferência para o curso diurno. Eu disse que isso era uma das preocupações mais burras que poderiam estar tendo naquele momento. Mas os professores tinham essa preocupação. E por conta disso o curso foi estruturado com um conteúdo programático muito diferente do curso diurno na grande maioria das disciplinas." (Reinaldo)

Na verdade, depreende-se que o inverso é o que ocorre, ou seja, a transferência de alunos do diurno para o noturno, uma vez que muitos terminam por ter que trabalhar e optam por não abandonar os estudos, sendo a Licenciatura a opção mais viável. Esse professor ainda diz que

“[...] A maioria das disciplinas não dava equivalência. E eu sempre disse que eu achava isso um absurdo: você ter dentro da própria instituição dois cursos, com as mesmas disciplinas, com conteúdos diferentes. Eu não consigo entender isso, quer dizer, o cara que faz Licenciatura e quer complementar para Bacharel, para Químico, ele tem que fazer mais de 50\% do curso de novo. [...]" (Reinaldo)

É importante ressaltar como é o pensamento do formador que, responsável pela formação do Licenciado, ainda assim está preocupado com que este obtenha também o grau de Bacharel. Percebe-se que existe uma tensão entre as falas de Danilo e Reinaldo, e que, apesar do primeiro estar consciente da formação diferencial que o licenciando precisa receber, é relevante destacar o desconhecimento dos formadores quanto ao currículo para a formação de professores, isto é visível nessas falas. Cumpre ainda ressaltar que, em relação a esse sujeito da pesquisa, é interessante observar como este não se coloca como construtor das disciplinas da matriz curricular e, sim, como simples 'montador' da mesma, como se os dois aspectos não estivessem imbricados. Ou seja, as disciplinas já estavam prontas e não se poderia alterá-las, pensando-as e modificando-as para um curso de formação de professores, somente cabendo a ele montar a matriz curricular. Esse pensamento está explicitado a seguir:

“[...] eu não participei do pensamento das disciplinas e sim da montagem da grade, como é que seria estruturado isso. [...]" (Reinaldo)

Com relação a José, do DQO, seu ponto de vista em relação a como são encaradas as questões relacionadas ao currículo, de forma geral, é explicitado a seguir:

“[...] o currículo aqui no Instituto de Química é sempre uma vergonha. A grande parte dos professores não está nem aí 
para o que eles chamam de currículo. Então as discussões sempre foram muito esvaziadas. Eu me lembro que uma determinada professora resolveu que ela gostaria de mexer no currículo e pelo que eu me lembro eu acho que foi ela que mexeu no currículo com o apoio aí de mais um ou dois professores, mas nunca houve uma discussão do que deveria ser um currículo de Química. Eno caso, nem do Bacharelado e nem da Licenciatura. E isso permanece até hoje." (José)

Essa é a expressão sobre como esse professor vê o corpo docente do IQ em relação às discussões curriculares. Entendo que o mesmo não especifica a qual corpo docente faz referência, se àquele do curso de LIQ ou ao do Instituto como um todo. Acrescenta ainda que

“[...] a questão mesmo de currículo eu nunca vi nenhum movimento, não diria sério porque é uma palavra muito forte, mas coordenado no sentido de realmente se discutir o quê que deveria ser então um currículo da Licenciatura e um currículo do Bacharelado." (José)

Já em relação a Fernando, do Departamento de Bioquímica, percebemos uma modificação de entendimento do tema:

"[...] a disciplina era praticamente idêntica à disciplina dada para a Biologia. E eu achava que a disciplina estava errada, que ela tinha que ter um foco mais químico. Aí eu levei isso para o departamento e o departamento me incumbiu de fazer as modificações. Eu fiz, então, as modificações que eu comecei a fazer no ano passado. Eu modifiquei a disciplina, diminui o número de práticas e aumentei o foco teórico dela e o enfoque químico. [...]" (Fernando)

Neste caso, percebemos que a disciplina foi modificada devido à experiência do docente em ministrar a mesma, e isto tem relação com o saber desse professor, visto que entendemos o sentido dado por Tardif (p. 255) "à noção de "saber" [como a de] um sentido amplo, ${ }^{31}$ que engloba os conhecimentos, as competências, as habilidades (ou aptidões) e as atitudes, isto é, aquilo que muitas vezes foi chamado de saber, saber-fazer e saber-ser."

O professor Roberto, do Departamento de Físico-Química, faz um relato das disciplinas desse departamento em que diz que elas também foram transpostas de outro curso e não pensadas para um curso de formação. Tal argumento pode ser comprovado a seguir:

"Na verdade eu me lembro bem como foi criada, inicialmente as disciplinas que receberam os códigos IF e IIF eram muito parecidas com as disciplinas da Farmácia que eram condensações das disciplinas Físico-Química I, Físico-Química II, o programa era mais ou menos uma condensação daquelas coisas e não houve discussão aprofundada nenhuma, não houve nenhuma discussão, por exemplo, que se voltasse para a Licenciatura, para a formação de profissionais na área de Educação. [...]" (Roberto)

Assim, o que pudemos perceber é que, de forma geral, com raras exceções, as disciplinas de Química oferecidas para o curso de LIQ não foram elaboradas, construídas para um curso de formação de professores. De acordo com o depoimento do professor abaixo, vê-se que a mudança na ementa da disciplina passa pelo docente que ministra a disciplina, sendo isso para tal docente um problema.

“[...] Se o professor achar que deve comentar sobre ou comparar com o que funciona no Ensino Médio, se ele tem essa experiência ou esse interesse ótimo, mas se não ele chega e vai cumprir uma ementa exatamente idêntica ao do diurno. E eu acho que isso é um problema. Eu acho que deveríamos mudar de alguma forma isso, mas não há nenhuma discussão no departamento a respeito disso, nem há grupo interessado eu acho no momento em fazer esse tipo de discussão, nem há massa crítica porque são poucos os professores que atuam nessa área, então acho que fica muito a questão individual. Felizmente os professores que já ministraram essas disciplinas têm esse interesse e sempre discutem pensando em alguma coisa do Ensino Médio. Mas isso é porque pessoalmente esses professores são envolvidos nesse aspecto, não porque haja algo escrito que leve, induza o professor a pensar dessa forma, mas acho que deveria."(Roberto)

No entanto, além de ser um problema a questão de tratar disciplinas de Química com enfoque para curso de formação de professores, dependendo de quem a ministra e de sua experiência, em nosso entendimento, isto deveria ser uma questão institucional, visto que, quando se transforma em questão pessoal, muitas vezes se torna algo perigoso, no sentido de que, em se mudando o professor, haveria um vácuo no processo. Isto está relacionado às reelaborações conceituais que são desconsideradas pelo corpo docente. Além dessa questão, é preciso considerar também o fator tempo quando se pensa em ministrar aulas no período noturno. Vê-se que

"[...] os alunos do noturno poderiam acompanhar os cursos do diurno tranquilamente. Eu apoiei isso baseado naquela minha experiência, que eu estava tendo, mas hoje eu sinto que não é possível, primeiro pela questão da carga horária que é menor no noturno, sem dúvida nenhuma e, principalmente, por se tratar do noturno eu particularmente não cumpro o segundo tempo todo. É muito complicado ficar aqui depois das 21:30, tanto para os alunos como para o professor, eu não cumpro o segundo tempo. Então nós temos uma carga horária que na verdade é significativamente menor do que a do diurno, vamos colocar 1 h por semana no mínimo menor do que a do diurno, consequentemente, é impossível dar o mesmo programa. Além disso, os alunos por maior deficiência em Matemática não acompanham da mesma forma que do diurno, então o programa não é tal como ele existe na ementa que hoje é a ementa oficial, ele não é todo cumprido. Eu sofri um pouco por conta disso, mas hoje eu relaxei, eu acho que cumprir a ementa é uma coisa importante, mas não é essencial. Dar ao aluno uma compreensão da coisa é mais importante do que cumprir completamente a ementa, é claro que eu não posso dar $20 \%$ da ementa, mas se eu der $70 \%$ da ementa, $75 \%$ da ementa e acho que o aluno ganhou uma compreensão eu fico mais satisfeito do que dar $100 \%$ da ementa correndo e ver que não aconteceu nada, que eu só estou cumprindo formalmente uma ementa."(Roberto)

Assim, além do tempo de aula à noite ser mais restrito, existem também as deficiências dos alunos, o que faz com que essas questões sejam levadas em consideração na elaboração de disciplinas para um curso de formação de professores.

Outro ponto trazido pelos entrevistados foram as mudanças curriculares:

“[...] Tiramos o Português e tiramos mais uma disciplina da Física que também o próprio Instituto de Física entendeu que o perfil do profissional, do licenciado em Química não exigia aquela disciplina. Nós cortamos essa disciplina que 
era Introdução a Física que ela tinha como objetivo fazer um resumo de toda Física que era dada no Ensino Médio pra fortalecer o estudante da Licenciatura em Física, então não se adequava para o estudante da Licenciatura em Química." (Danilo)

Essas foram disciplinas excluídas da matriz curricular e, ainda de acordo com Danilo, o problema que acompanha muitos cursos de Licenciatura é a questão dos blocos de disciplinas específicas e de pedagógicas. Percebe-se que, mesmo que as últimas sejam iniciadas no início do curso, não existe uma conexão entre as disciplinas e nem mesmo dentro delas com a área específica de ensino, e, neste caso, a Química.

"[...] as disciplinas de conteúdo químico e as disciplinas da Faculdade de Educação, elas vão paralelas, elas não se cruzam, elas não se entendem e esse realmente é o problema [...]"(Danilo)

De acordo com a literatura atual da área, mesmo não existindo o modelo " $3+1$ " em muitos cursos de licenciatura, esse modelo persiste velado, visto que há certa dificuldade em se articular as disciplinas específicas com as pedagógicas.

“[...] foi formado para ter um professor que é químico. É um químico que dá aula. Como a grade de todas as Licenciaturas... [...]"(Ivan)

Assim, a formação obtida pelo Licenciado não está adequada para este ser um professor e, sim, um Químico. Concordando com Schnetzler (p. 22), ${ }^{32}$ o curso termina por ser "um bacharelado "contaminado" com algumas disciplinas pedagógicas" e o profissional é formado para um campo de atuação desconhecido para o futuro professor.

Com relação à categoria Currículo, o Prof. Roberto diz:

“[...] Porque ele não é um currículo voltado para a formação de professores. É um currículo adaptado de um curso de Química para... adaptado entre aspas, sem muita discussão. [...]” (Roberto)

E que esse currículo precisava ser modificado no sentido de ser pensado com outra conformação, uma vez que

"A Licenciatura precisava de mais formação específica na área. Eu acho. Há pouco envolvimento da Faculdade de Educação. Eu acho.” (Roberto)

Nesse sentido, o professor explicita o pouco diálogo entre as duas unidades IQ e FE, na estruturação do currículo. No entanto, não deixa de fazer críticas ao próprio Instituto, pois, de acordo com Roberto, é preciso modificar o currículo com relação às disciplinas de ensino, também,

"[...] ]aumentar a carga, vamos dizer, na parte da Educação de Química mesmo. Eu acho que o curso é muito técnico ainda. Técnico de Química. Não que não seja importante. Eu acho que é importante, mas eu acho que tem que ter mais peso na área de Educação. Acontece que existe uma questão. Muita gente que está fazendo Licenciatura em Química não vai ser professor. Isso é um gravíssimo problema. Mas eu acho que a gente não pode criar o curso por conta disso. Eu acho que a gente tem que criar o curso para formar professor. Quem não for ser, quem não quiser ser professor, paciência, mas a carga tem que ser voltada para a formação do professor. Eu acho que a gente tem que pensar nisso. Que a gente quer formar professor." (Roberto)

Ou seja, se compreendemos o currículo nesta pesquisa da perspectiva de Goodson (p. 213) como sendo "uma construção social", ${ }^{33}$ pelo depoimento, nos parece que o currículo é compreendido como um aglomerado de disciplinas dispostas em blocos.

Outro professor, Álvaro, faz uma crítica ao currículo quando diz:

"Eu acho que esse currículo, do jeito que está colocado, ele não permite qualquer possibilidade de transformação. Formar nenhum professor com possibilidade de transformar qualquer coisa. [...]”(Álvaro)

Assim, para esse sujeito, o currículo não permite formar o professor para a sociedade atual. Mas por quê? De acordo com Geraldo, professor da Faculdade de Educação, isso pode estar baseado em

"[...] uma crença de que você organizar o currículo com disciplinas, da perspectiva da acomodação de grade é o caminho. Essa é uma visão profundamente restrita de currículo. Quando você pensa no currículo como sendo aquela tradução da organização da grade. Então você pensa, que eu vou melhorar o curso, quando eu amplio o curso, por exemplo. Em vez de pensar: eu melhoro o curso ou eu repenso o curso, quando eu qualitativamente imagino que concepção de curso é esse."(Geraldo)

Assim, para esse professor:

"[...] Quer dizer essa questão de formação de professor centrada na disciplina é que eu critico. Você ter uma formação de professor centrado nas disciplinas. De como as disciplinas podem contribuir quase que isoladamente. Eu penso, na verdade, como essas disciplinas poderão trabalhar num conjunto que seria organicamente inteirado, organicamente construído para você pensar uma filosofia de formação de professores. Você compreende? Todas as experiências curriculares são muito centradas na organização de disciplinas. Ou seja, leia-se: currículo como grade. [...]"'(Geraldo)

De acordo com Lopes (p. 34), "a integração das disciplinas é relacionada muito mais com uma atitude diante do conhecimento do que com uma concepção diversa desse mesmo conhecimento." Assim, para essa autora, "o foco é a defesa de um sujeito - cientista ou profissional - que se relacione de maneira diferenciada com os saberes e que esteja disposto a cooperar nos processos de produção de conhecimento", ou seja, para Lopes (2008):

A especialização permanece como forma de regulação do conhecimento, mas passa a ser necessário um especialista capaz de dialogar com outros campos do saber - por ser dotado de uma cultura geral que permite conhecer os códigos essenciais a tal diálogo. Pela ênfase nas competências e habilidades, é também compreendido que o acesso a essa cultura geral faculta o domínio de certas formas de pensamento e de operar com o conhecimento, de certas atitudes consideradas convenientes no contexto social do mundo globalizado (p. 34).

A formação desse sujeito citado por Lopes parece ser aquele esperado pelo Prof. Geraldo, mas não aquele que se espera formar com o currículo do curso investigado. Pensar esse currículo integrado 
também possibilita trazer para a reflexão a clássica análise realizada por Basil Bernstein e citada por Lopes e Cunha e Leite sobre os currículos em estruturas de coleção e integração. ${ }^{35,36}$ Com relação à estrutura de coleção, são definidos conteúdos em relações fechadas, separados uns dos outros, com classificação e enquadramentos fortes, isto é, de acordo com Lopes (2008) citando Bernstein,

[...] um forte enquadramento reduz o poder do aluno sobre o conhecimento que ele recebe, quando e como ele o recebe - e aumenta, por sua vez, o poder do professor nas relações pedagógicas. Um alto grau de classificação, por outro lado, reduz o poder do professor sobre o que ele transmite, uma vez que ele tem de se manter nos limites impostos entre as disciplinas (p. 37).

Com relação às estruturas de integração, de acordo com Bernstein citado por Cunha e Leite, aquelas são relações mais tênues, com enquadramento e classificação fracos, sem limites definidos entre os conteúdos, ou seja, com relações abertas, interdisciplinares. Em meu entendimento, e com base nos depoimentos dos professores citados anteriormente, os currículos do curso parecem se enquadrar nas estruturas de coleção, em que as relações sobre quem 'transmite' o conhecimento são assimétricas sobre quem 'recebe' esse conhecimento.

Em relação à categoria Reformas curriculares, busquei saber se os professores sabiam sobre as reformas curriculares que aconteceram no curso de LIQ, no período de 1993 a 2005 e, como resposta, a maioria disse não saber e não ter participado das mesmas. Isto pode ser depreendido pelos depoimentos de Fernando, do Departamento de Bioquímica, quando diz:

"Não. Eu só dava minhas aulas e não sabia o que estava acontecendo. [...]"

No entanto, Danilo, professor do DQI e ex-coordenador do curso, diante de meu espanto em querer saber o porquê de os professores não acompanharem as reformas que aconteceram no curso, explicou como se deu o processo, explicitando que:

"Em princípio, essas reformas são feitas sem consulta ou com breve consulta aos departamentos. São decididas pelo conselho que é ligado com a direção, com a coordenação do curso. Então, eu diria que a gente quase não acompanha isso. Essas coisas passam assim. Por exemplo, acompanhei no período que eu era Coordenador, quando a gente fez algumas modificações, com aprovação do conselho de Licenciatura. Essas outras sugestões, propostas, modificações do currículo a gente não acompanha."(Danilo)

Portanto, dos 7 professores entrevistados, não consegui obter respostas positivas em relação a essa questão, uma vez que foi constatado que, em sua maioria, os professores não acompanham as reformas curriculares e, em meu entendimento, parece haver certo alheamento dos formadores de professores com relação a esta questão de tanta importância, uma vez que são reformas curriculares que estavam em curso. E, uma vez que o currículo vai sendo constituído pelos sujeitos ao longo de sua história, seria importante a participação desses sujeitos que são formadores durante esse processo. Por outro lado, quando esses formadores dizem não saber das reformas curriculares, os mesmos estão, de certa forma, participando pela omissão; isto então não pode ser considerado um aspecto de estabilidade do currículo?

Com relação à categoria Concepção de formação de professores do curso, investigamos se os formadores sabem dizer qual é realmente a concepção do curso que possuem e muitos deles tiveram dificuldades em responder as questões relacionadas a esta categoria.

Pelo depoimento de Reinaldo, professor do DQA, pudemos ver a dúvida quanto a essa concepção, quando diz que:

"[...] falta realmente fazer um grande debate interno com todas as pessoas envolvidas com o curso, de o que é realmente a filosofia deste curso. Qual é a grande filosofia do curso de Licenciatura? Eu acho que isso também falta um pouco para o curso diurno, para o curso de formação de Químico com atribuições tecnológicas. Existe uma grade, existe um objetivo, cada um faz a sua parte, mas eu acho que não há um grande, pelo menos eu nunca vi um debate da filosofia global do curso. Realmente, eu nunca vi. Desse tempo todo que eu estou aqui dentro e, realmente, eu nunca vi uma discussão desse nível. $O$ que nós queremos com esse curso? Qual o nosso objetivo com esse curso? O que nós precisamos fazer para atingir esse objetivo? [...]"(Reinaldo)

Por outro lado, Danilo, do DQI, fala que

“[...] Alguns poucos professores pensam outros aspectos. Que o professor tem que ter uma visão mais ampla, o professor tem que estar acompanhando tudo que o Ministério da Educação tem colocado, discutido. Então, um envolvimento mais do professor engajado, do professor ativo, político, que está procurando e conhecendo os problemas etc. Mas isso são poucos professores que fazem isso e é o que eu estou te dizendo, são poucos os que dão aula para o curso de Licenciatura."(Danilo)

Para outro professor do DQO, Álvaro, é difícil deslocar a sua concepção do que é entendido pelo curso, e, em suas palavras:

"Eu acho que é muito arraigado ainda, é, uma certa visão que o importante é esse conteúdo. Eu também acho. A minha visão é que isso é necessário, mas isso aí não é suficiente. É, e que, não é só aqui no Instituto de Química, senão na universidade toda, as disciplinas pedagógicas não têm nenhum sentido. Isso é um absurdo aquilo, e a pessoas pensam muito como Químico mesmo."(Álvaro)

Com relação aos professores da FE, para Geraldo, existe

“[...] Ainda uma noção de formar professores muito ligada a habilidades técnicas, da realização técnica da disciplina, do como ensinar, do como fazer. Ora, como ensinar e como ensinar bem? A pergunta é legítima. A questão toda é que isso não se realiza só com tecnicalidades. Você entende? Se realiza por um esboço, um escopo teórico, que é não só grande, não só denso, não só profundo, mas também específico. Você entende? Ou seja, é... A noção que os professores aqui têm, ou alguns que eu conheço aqui dentro, é uma noção que de certa parte concebe o ato de ensinar como alguma coisa inerente a um dom."(Geraldo)

E, para Susana, a concepção de formação de professores do curso estava ligada a cada departamento, visto que

“[...] tem várias tensões presentes. Tem a questão tecnicista presente. Então, existem tendências tecnicistas presentes ali em algumas disciplinas. Tem umas tendências de campo, por exemplo, as disputas de Química Orgânica, Química Inorgânica. Isso é uma questão clássica do campo!" 
A concepção de formação de professores não fica clara no discurso dos formadores de professores e nem está expressa nos documentos do curso investigado.

Muitos professores vêem o ato de ser professor como um dom e isso pode ser visto no depoimento de Reinaldo

\section{"[...] ninguém pega uma pessoa e a transforma em professor. Ou a pessoa é professora ou não é. Você pode até melhorá-lo. Então ser professor já é um dom. O cara nasce professor. Ele tem um dom. Você melhora. Melhora o quê? É, colocando com ele técnicas de ensino. Melhorando a postura dele, a maneira como ele aborda determinado assunto. Isso você consegue melhorar. [...]"(Reinaldo)}

Nesta visão, ainda está implícita a instrumentalização do professor, ou seja, dotá-lo de instrumentos para que o mesmo dê uma boa aula. Podemos comparar o dom de que fala o professor acima àquilo que Pestel chama de ensinar como arte,$^{37}$ pois quando o ensino é visto desta forma, não existe um compromisso em se analisar as práticas usadas em sala de aulas. Desta maneira, as práticas acabam por serem baseadas no sistema de crenças, visto que, para este autor, o ensino precisa ser entendido como ciência, pois somente desta maneira haverá o compromisso com o aprendizado dos alunos. Nesse sentido, a impressão que temos é que o formador de professor se desobriga de seu papel de formador de professores, pois, se em seu entendimento ser professor é um dom, a ele caberia então qual papel?

Dos 7 professores entrevistados apenas 3 têm consciência de que o currículo deveria contemplar reelaborações conceituais e ser melhor integrado como um todo, no entanto, esses sujeitos não sabem como fazer isso. Isso faz com que o currículo do curso, ao invés de formar o Licenciado, esteja apto a formar um Químico técnico que está habilitado para ministrar aulas, apresentando em sua matriz um percentual alto de disciplinas de Inorgânica. Isto se deve à influência política e histórica desse departamento no IQ/UFRJ ${ }^{38}$ Este alto índice de disciplinas específicas na matriz curricular marca uma série de desavenças com a Faculdade de Educação, dentre elas, a de que o curso é de segundo nível. Devido à tradição do IQ/UFRJ em formar Químicos, o curso de Licenciatura apresenta uma série de dificuldades para se consolidar como curso de formação de professores devido à própria história do Instituto.

\section{CONSIDERAÇÕES FINAIS}

Com relação às três hipóteses de Goodson, o que apreendemos é que, se compreendemos a $1^{\text {a }}$ hipótese como as disciplinas que compõem o currículo do curso de LIQ, elas são construções de cada um dos cinco departamentos (DQA, DBq, DFQ, DQI e DQO), portanto, amálgamas resultantes de tradições desses departamentos com suas respectivas histórias, apresentando relações para além dos aspectos institucionais. Em relação à $2^{\text {a }}$ hipótese, há um distanciamento dessas disciplinas acadêmicas das tradições utilitárias e pedagógicas e, uma aproximação das tradições acadêmicas, assim, concordando com a hipótese de Goodson. E, por fim, com relação à $3^{\text {a }}$ hipótese, o debate curricular envolve conflito por status, recursos e território, visto como a disputa por disciplinas no currículo, ou seja, a forma como as disciplinas estão distribuídas na matriz curricular, o que envolve uma disputa vista através da distribuição dessas disciplinas na matriz curricular do curso de LIQ e a predominância de determinado número de disciplinas de determinado departamento em detrimento de outro. Este aspecto implica em disputas por território e também por recursos.

Quanto às tradições pedagógicas, utilitárias e acadêmicas, a tradição utilitária está relacionada com o ensino de Química que será ministrado pelo futuro professor, licenciado, formado pelo curso de LIQ, na escola e, de acordo com Goodson, está relacionado ao conhecimento de baixo status. Por outro lado, a tradição acadêmica está relacionada com a formação científica oferecida pelo curso de LIQ. Ademais, outra questão diz respeito à matriz curricular, pois se realizando sua análise aquela apresenta características de coleção, pois os conteúdos são encerrados em si mesmo, não mantendo relações com outras disciplinas.

Com relação aos documentos pesquisados do curso de LIQ e os depoimentos de alguns sujeitos da pesquisa, ressalte-se a importância do profissional formado ter a possibilidade de ser registrado pelo CRQ e possuir as sete atribuições desse Conselho. Assim, de acordo com a Resolução Normativa $\mathrm{n}^{\circ} 36,{ }^{39}$ de 25/4/1974, o formado é denominado “profissional da Química” e recebe o título de Químico por ter as atribuições. Mas não é contraditório o profissional receber o título de Químico e Licenciado? Entende-se que é licenciado porque cursou o curso de Licenciatura em Química e Químico porque pela natureza do currículo, de acordo com as disciplinas cursadas, este tem direito às atribuições e, portanto, ao título.

No entanto, com relação ao currículo? Qual professor o curso pretende formar? O reflexivo, o pesquisador ou aquele que, sabendo "muita Química", irá saber dar "muita aula"? Um curso que, do ponto de vista do currículo proposto, possui uma discussão avançada, com as disciplinas pedagógicas apresentadas desde $\mathrm{o} 3^{\circ}$ período, mas, do ponto de vista da ação dos formadores a categoria institucional 'formação de professores' é a da racionalidade técnica, em que importa ministrar conteúdos específicos e, posteriormente, aplicá-los na prática.

Com relação aos depoimentos dos formadores de professores, percebemos que os mesmos trazem alguns aspectos importantes a serem ressaltados, tais como: a não integração entre as disciplinas específicas e pedagógicas; a persistência da dicotomia entre a teoria-prática, e isso pode ser observado pelo desmembramento de disciplinas na matriz curricular ocorrida com disciplinas do DQA em 2005, em que foram divididas em teórico-experimentais; a realização do estágio supervisionado somente ao final do curso; o desconhecimento da realidade da escola básica pelos docentes que formam os futuros professores; a permanência da realização do Projeto de Final de Curso no semestre final do curso, sem tempo hábil para desenvolvimento de pesquisa em ensino de Química. Muitas dessas características são marcas do modelo da racionalidade técnica e mostram a tradição de um curso que possui em sua história a marca da formação do Químico e não a do Licenciado. Para que a formação do Licenciado ocorresse, seria necessário que, na formação de professores, a discussão a respeito da reelaboração conceitual acontecesse, e, com isso, fosse possível formar o profissional que os formadores de professores desconhecem.

\section{AGRADECIMENTOS}

Gostaríamos de agradecer as valiosas contribuições da Profa. R. P. Schnetzler ao texto, aos professores entrevistados e à bolsa CAPES concedida para a realização da pesquisa.

\section{REFERÊNCIAS E NOTAS}

1. Pérez-Gómez, A. P. Em Os professores e a sua formação; Nóvoa, A., org.; Publicações Dom Quixote: Lisboa, 1995, cap. 5.

2. Goodson, I. F.; A construção social do currículo, Educa: Lisboa, 1997.

3. Goodson, I. F.; The changing curriculum: studies in social construction, New York: Peter Lang: New York, 1997.

4. Goodson, I. F.; O Currículo em Mudança - Estudos na construção social do currículo, Porto Editora: Porto, 2001, cap. 8.

5. Goodson, I. F.; Currículo: teoria e história, $7^{\mathrm{a}}$ ed., Vozes: Petrópolis, 2005. 
6. Goodson, I. F.; Learning, Curriculum and Life Politics: the selected works of Ivor F. Goodson, Routledge: Canada, 2005.

7. Goodson, I. F.; Rev. Bras. Educ. 2007, 12, 241.

8. Goodson, I. F.; Educ. Rev. 2007, 45, 121.

9. Ata de reunião da Congregação de 14/07/1992. Acervo do IQ/UFRJ.

10. Convênio do Ministério da Educação (MEC) - Banco Interamericano de Desenvolvimento (BID) e não existem informações detalhadas acerca deste convênio neste ano. No entanto, de acordo com Lopes (2008, p. 21) "as relações com as agências de fomento, como o BID e o Banco Mundial, desenvolveram-se de forma bastante estreita na vigência dos dois mandatos presidenciais de Fernando Henrique Cardoso" (1994 a 2002), em decorrência de as lideranças das reformas que aconteceram no MEC terem atuado nessas agências.

11. Santos, W. L. P.; Gauche, R.; Silva, R. R.; Quim. Nova 1997, 20, 675.

12. Mazzetto, S. E.; Sá Carneiro, C. C. B.; Quim. Nova 2002, 25, 1204.

13. Arroio, A.; Honório, K. M.; Homem-De-Mello, P.; Weber, K. C.; da Silva, A. B. F.; Quim. Nova 2008, 31, 1888.

14. Arroio, A.; Rodrigues Filho, U. P.; da Silva, A. B. F.; Quim. Nova 2006, 29, 1387.

15. da Silva, R. M. G.; Schnetzler, R. P.; Quim. Nova 2005, 28, 1123.

16. da Silva, R. M. G.; Schnetzler, R. P.; Quim. Nova 2008, 31, 2174.

17. Maldaner, O. A.; Quim. Nova 1999, 22, 289.

18. Cunha, M. I. da; O bom professor e sua prática, $3^{\text {a }}$ ed., Papirus: Campinas, 1994.

19. Esteves, M. Em Sentidos da Pedagogia no Ensino Superior; Leite, C., org.; CIIE/Livpsic: Porto, 2010, cap. 3.

20. Bogdan, R. C.; Biklen, S. K.; Investigação Qualitativa em Educação, Porto Editora: Porto, 1994.

21. Macedo, E. Em Pesquisa no/do cotidiano das escolas sobre redes de saberes; Oliveira, I. B.; Alves, N., orgs.; DP\&A: Rio de Janeiro, 2001, p. 131-149.

22. Para um maior aprofundamento sobre a pesquisa documental realizada ver Massena, E. P.; Tese de Doutorado, Universidade Federal do Rio de Janeiro, Brasil, 2010.
23. Richardson, R.; Pesquisa social, Atlas: São Paulo, 1999, cap. 13.

24. Alberti, V.; Manual de história oral, $2^{\mathrm{a}}$ ed., FGV: Rio de Janeiro, 2004.

25. Moraes, R.; Galiazzi, M. C.; Análise textual discursiva, Ed. Unijuí: Ijuí, 2007.

26. Torres, J. R.; Gehlen, S. T.; Muenchen, C.; Gonçalves, F. P.; Lindemann, R. H.; Gonçalves, F. J. F.; Rev. Bras. Pesq. Educ. Ciênc. 2008, 2.

27. Gonçalves, F. P.; Tese de Doutorado, Universidade Federal de Santa Catarina, Brasil, 2009.

28. Cirino, M. M.; Souza, A. R.; Rev. Elet. Ens. Cienc. 2010, 9, 125.

29. No curso de LIQ são oferecidas disciplinas pelos Institutos de Física, Matemática, Geociências, Filosofia e Ciências Sociais e pela Faculdade de Letras, no entanto, como o maior percentual de disciplinas é oferecido pelo IQ e pela FE e estas são nosso objeto de pesquisa, focalizamos nossa atenção nestas duas unidades.

30. Moraes, R.; Ciênc. Educ. 2003, 9, 191.

31. Tardif, M.; Saberes docentes e formação profissional, $8^{\mathrm{a}}$ ed., Vozes: Petrópolis, 2007.

32. Schnetzler, R. P. Em Ensino de Ciências: fundamentos e abordagens; Schnetzler, R. P.; Aragão, R. M. R., orgs.; Ed. Vieira: Campinas, 2000.

33. Goodson, I. F. Em ref. 4, cap. 10.

34. Lopes, A. R. C.; Políticas de integração curricular, Ed. da UERJ: Rio de Janeiro, 2008, cap. 3.

35. Para maior aprofundamento ver Young, M.; Educ. Soc. 2007, 28, 1287. É feita uma discussão a respeito da classificação e enquadramento do conhecimento escolar baseado em Bernstein.

36. Cunha, M. I. da; Leite, D. B. C.; Decisões pedagógicas e estruturas de poder na universidade, Papirus: Campinas, 1996.

37. Pestel, B. C.; J. Chem. Educ. 1990, 67, 490.

38. Massena, E. P.; dos Santos, N. P.; Quim. Nova 2009, 32, 2238.

39. Dá as atribuições aos profissionais da Química e estabelece critérios para a concessão das mesmas, em substituição à Resolução Normativa no 26. Fonte: http://www.crq3.org.br/institucional_legislacao.htm, acessada em Abril 2010. 